\title{
LETTER
}

\section{Reducing sensory input in critically ill patients: are eyemasks a blind spot?}

\author{
Koen S Simons ${ }^{1,2 *}$, Mark van den Boogaard ${ }^{2}$ and Cornelis PC de Jager ${ }^{1}$ \\ See related research by Van Rompaey et al., http://ccforum.com/content/16/3/R73
}

We read with interest the article by Van Rompaey and colleagues [1] reporting that earplugs may be useful in the prevention of delirium in non-ventilated ICU patients. Unfortunately, they did not report any potentially negative effects of earplugs related to sensory deprivation - for example, restlessness, discomfort, or anxiety.

In non-ventilated critical care patients the combination of earplugs and eyemasks were effective to improve sleep [2], and the use of eyemasks, in healthy volunteers, in a simulated ICU environment led to improved nighttime sleep and higher nocturnal melatonin levels [3]. Whether or not these positive results also apply to intubated ICU patients is not known and the mentioned possible disadvantages might especially occur in this vulnerable patient group. Nevertheless, the Dutch guideline on delirium management states that the use of nighttime eyemasks should be considered [4]. As the use of eyemasks in intubated patients could very well lead to a feeling of sensorial deprivation and its feasibility in critically ill patients is not clear, we analyzed 18 ICU patients who were offered the choice of wearing a nightmask from 10 p.m. to 6 a.m. (Table 1). The need for informed consent was waived since the use of eyemasks is a part of national delirium guidelines and participation was on a voluntary basis.

Eleven patients (61\%) were willing to wear a nightmask on average on $28 \%$ (median 4 nights, range 1 to 5 ) of nights on the ICU. In these patients self-perceived quality of sleep, using a visual analog scale (VAS), improved from 6.6 (5.9 to 8.2$)$ to $7.5(7.0$ to 8.0$)(P=0.041)$ when the mask was worn. In $72 \%$ of cases, the mask was refused or taken off prematurely due to restlessness $(30 \%)$, discomfort $(20 \%)$, or anxiety (11\%).

While eyemasks might improve sleep in selected patients, it also may lead to feelings of discomfort and

*Correspondence: k.simons@jbz.nl

'Departement of Intensive Care, Jeroen Bosch Ziekenhuis, 5200 ME,

's-Hertogenbosch, The Netherlands

Full list of author information is available at the end of the article
Table 1. Patient characteristics

\begin{tabular}{lc}
\hline Patient characteristic & $\mathbf{N}=\mathbf{1 8}$ \\
\hline Age (years \pm SD) & $71 \pm 7$ \\
Male (\%) & $11(61 \%)$ \\
APACHE-II score \pm SD & $26 \pm 6$ \\
ICU LOS (days, median (IQR)) & $8(5$ to 17$)$ \\
Delirium & $6(30 \%)$ \\
Diagnosis group & \\
Surgical & $5(28 \%)$ \\
Medical & $13(72 \%)$
\end{tabular}

APACHE, Acute Physiology and Chronic Health Evaluation; LOS, length of stay; $\mathrm{IQR}$, interquartile range; $\mathrm{SD}$, standard deviation.

anxiety in mechanically ventilated ICU patients and therefore its standardized use should be used with caution and only on a voluntary basis in this specific group.

\section{Competing interests}

The authors state that they do not have any competing interests.

\section{Author details}

'Departement of Intensive Care, Jeroen Bosch Ziekenhuis, $5200 \mathrm{ME}$ 's-Hertogenbosch, The Netherlands. ${ }^{2}$ Departement of Intensive Care, Radboud University Nijmegen Medical Centre, 6500 HB, Nijmegen, The Netherlands.

Published: 16 July 2012

References

1. Van Rompaey B, Elseviers MM, Van Drom W, Fromont V, Jorens PG: The effect of earplugs during the night on the onset of delirium and sleep perception: a randomized controlled trial in intensive care patients. Crit Care 2012, 16:R73.

2. Richardson A, Allsop M Coghill ETurnock C: Earplugs and eye masks: do they improve critical care patients'sleep? Nurs Crit Care 2007, 12:278-286.

3. Hu RF, Jiang $X Y$, Zeng $Y M$, Chen $X Y$, Zhang $Y H$ : Effects of earplugs and eye masks on nocturnal sleep, melatonin and cortisol in a simulated intensive care unit environment. Crit Care 2010, 14:R66.

4. Spronk PE, van Eijk MMJ, van den Boogaard M, van der Jagt M, Kuiper MA, Smit EGM, Slooter AJC: NVIC Richtlijn Delirium op de Intensive Care [http:// www.nvic.nl/download.php?id=573]

doi:10.1186/cc11402

Cite this article as: Simons KS, et al:: Reducing sensory input in critically ill patients: are eyemasks a blind spot? Critical Care 2012, 16:439. 